\title{
$\operatorname{arCOS} D E S I G N$
}

\section{Instrução para Simbiose}

Carolina Correia dos Santos (PACC/FAPERJ (pós-doc 10)/UFRJ, Brasil) caro.corre.san@gmail.com

UFRJ - Programa Avançado de Cultura Contemporânea - PACC

Av. Horácio Macedo, 2151 - Cidade Universitária

Ilha do Fundão, RJ, Brasil, CEP: 21941-917 


\section{Instrução para Simbiose}

Resumo: este texto foi apresentado oralmente na segunda edição do seminário Design.com: Articulações, Expansões, Conexões. Consiste em uma narrativa que visa conectar atores e obras inusitados, desconhecidos uns aos outros, mas que, se devidamente articulados, podem invocar uma história que habite a Chthulucene de Donna Haraway. Os protagonistas, além da própria Haraway, são Gilles Deleuze, Marilyn Strathern, Isabelle Stengers, Beatriz Chachamovits, Davi Kopenawa, o Crochet Coral Reef os mitopoemas yanomami.

Palavras-chave: simbiose, narrativa, fim do mundo, feminismo.

\section{Instructions for Symbiosis}

Abstract: This text was presented in the second edition of Design.com: Articulações, Expansões, Conexões. It consists of a narrative that aims to connect actors and works unknown to each other in an unusual way. However, if properly articulated, this web may invoke a story that inhabits Donna Haraway's Chthulucene. The protagonists, besides Haraway herself, are Gilles Deleuze, Marilyn Strathern, Isabelle Stengers, Beatriz Chachamovits, Davi Kopenawa, Crochet Coral Reef the Yanomami mythopoemas.

Keywords: symbiosis, narrative, end of the world, feminism. 
Começo agradecendo: o convite para participar da segunda edição do seminário Design.com: Articulações, Expansões, Conexões, me ativou a imaginação desde o princípio, quando li sua descrição mais geral e a descrição desta mesa. Poucas, me parecem, são as instâncias de trabalho assim abertas. Vocês verão que instâncias abertas e associações inusitadas são temas caros a mim. Assim como a narrativa. Talvez seja essa a principal razão deste convite. E eu espero contar uma boa história a vocês.

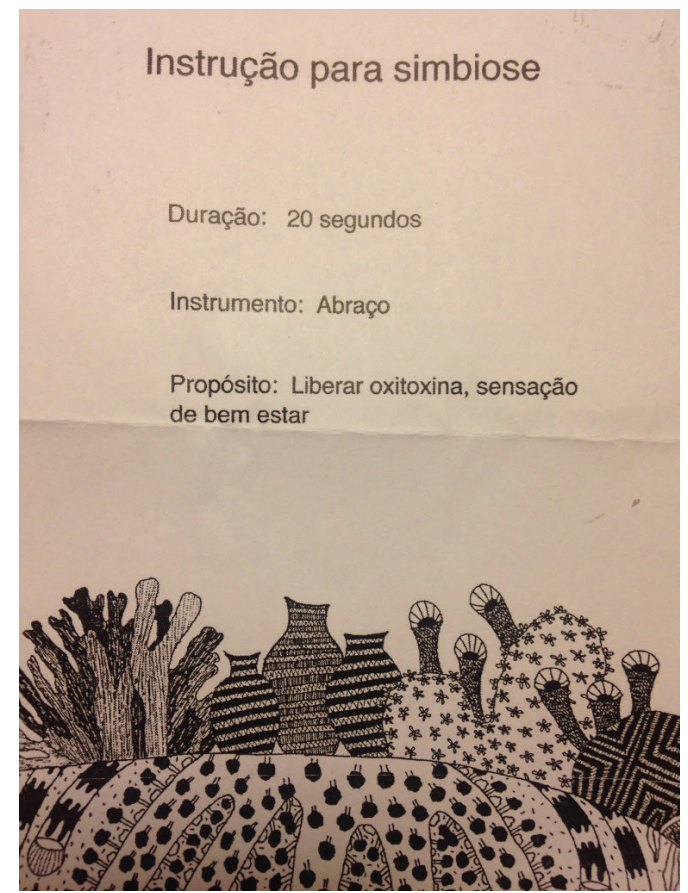

Figura 1. Folheto de divulgação da artista (fonte: arquivo pessoal - fotografia de Carolina Correia dos Santos/divulgação autorizada pela artista).

Há cerca de dois anos, eu desenvolvia um projeto de pesquisa que vinculava meu interesse pelas narrativas do fim do mundo às artes. Eu já me embranhara em campos discursivos distintos; pensava sobre o Antropoceno e as discussões das ciências sociais, pensava sobre a literatura - e a ficção - como o discurso que poderia, talvez e paradoxalmente, dar contar do fim do mundo. Deleuze (2011) tem um texto curto e belíssimo sobre a literatura em que enuncia uma formulação que ficará famosa e pode ser resumida assim: "a literatura é a invenção de um povo que falta". Ele diz: "Fim último da literatura: pôr em evidência no delírio essa criação de uma saúde, ou essa invenção de um povo, isto é, uma possibilidade de vida. Escrever por esse povo que falta..." (p. 16). A literatura, neste sentido, funcionaria como o suplemento das ciências sociais, posto que é ela que pode escolher, entre possibilidades reais e virtuais, os nomes, os termos, as gentes e as coisas que usa. O fim do mundo, ainda, não aconteceu. Já me parecia, há dois anos, que a literatura - ou algo parecido a ela - poderia falar melhor sobre o que falta. 
Proposto por Paul Crutzen e Eugene Stoermer como a designação mais adequada para a atual idade geológica da Terra, "Antropoceno" teria se iniciado com a Revolução Industrial, ou, o que se tornou oficial, a partir da década de 1950. Houve, por parte dos estudiosos críticos da modernidade, em geral, uma boa aceitação do nome. Antropoceno evidenciava a ação nociva do anthropos sobre a Terra, fazia emergir claramente os problemas ecológicos que os homens haviam criado e, assim, denunciava o capitalismo, o colonialismo, o imperialismo, etc.

Mas dentro do grupo que de modo mais instigante discutia a questão, a pensadora feminista Donna Haraway surgia como dissonância. Longe de discordar da ação humana predatória dos últimos séculos, Haraway se mostrava insatisfeita com a centralidade de antropos em Antropoceno, que sustenta a crença numa espécie diferenciada e independente de outras. Se as grandes e melhores descobertas do mundo intelectual e acadêmico dos últimos tempos predicam que nenhum bom trabalho intelectual surge das premissas do individualismo e do individualismo metodológico, e se as ciências naturais têm cada vez mais confiado e confirmado que os seres que habitam hoje nosso mundo são aqueles que vivem e viveram em relação, ou seja, que ser uma espécie é tornar-se uma espécie juntamente com outra(s); se esses são os dois melhores insights da nossa intelectualidade e verdadeiras revoluções culturais do nosso tempo, pergunta Haraway, por que nomear uma nova época a partir do antropos?

Para Haraway, importa que histórias contam histórias. Que nomes mobilizamos? Quem chamamos para acompanhar-nos numa narrativa? Seu incômodo se formava a partir do alerta de pensadoras como a antropóloga Marilyn Strathern, a quem Haraway sempre alude. Strathern explica que as premissas do debate feminista "não são as de um projeto incompleto" porque "a ideia de um projeto incompleto sugere que a completude poderia ser possível; o debate feminista é um debate radical, na medida em que compartilha com outros radicalismos a premissa de que a completude é indesejável" (STRATHERN, 2006, p. 53). Enquanto eu buscava compreender o lugar de enunciação de Haraway, o literário - não só uma obra literária - tornava-se uma ferramenta fundamental para narrar. Se a completude é indesejável, como afirma Strathern, narrativas feministas operam como a literatura na definição de Deleuze: "Escrever não é certamente impor uma forma (de expressão) a uma matéria vivida. A literatura está antes do lado do informe, ou do inacabamento ... Escrever é um caso de devir (DELEUZE, 2011, p. 11)".

Assim, na narrativa do fim do mundo de Haraway, o mundo não está exatamente acabando, nem os homens são exatamente os culpados. Haraway propõe uma alternativa mais ambígua e possivelmente mais criativa, que, portanto, possa constituir-se uma história sem fim necessariamente (muito menos 
um fim já conhecido), nem finalidade. Chthulucene refere-se à figura abissal e proveniente das entranhas da Terra, do caos, da mistura, de um conjunto, deste modo, simpoiético, que desenvolve-se em relação com. Na sua Chthulucene, os homens e outros seres, os humanos com outros seres, ainda podem fazer coisas criativas, vivas, indeterminadas, uma quimera de histórias, de associações inusitadas e de questionamentos. Nem tudo está previsto. Tudo não pode estar previsto. Nem tudo pode ser conhecido ou reconhecido. Por isso nomear também abre um porvir, além de evocar este ou aquele imaginário.

Isabelle Stengers (2015) diz que "nomear não é dizer a verdade, e sim atribuir àquilo que se nomeia o poder de nos fazer sentir e pensar no que $o$ nome suscita" (p. 37). Stengers nomeia os nossos tempos e espaço "Gaia". Diferente da Pachamama, da Terra que acollhe, ou mesmo da natureza que se vinga, Gaia é a que faz intrusão e se faz sentir, sem, de fato, se importar com "vinganças” ou "acertos de contas". "Nomear Gaia como 'a que faz intrusão' é também caracterizá-la como cega aos danos que provoca, à maneira de tudo o que é intrusivo. ... Trata-se de pensar aqui a intrusão, e não o pertencimento" (STENGERS, 2015, p. 37).

Gaia é o nome escolhido por James Lovelock e Lynn Margulis, no início dos anos 1970. Os dois cientistas

incorporavam pesquisas que contribuem para esclarecer o denso conjunto de relações, articulando o que as disciplinas científicas tinham por hábito tratar separadamente: os seres vivos, os oceanos, a atmosfera, o clima, os solos mais ou menos férteis. Dar um nome, Gaia, a esse agenciamento de relações. Aquilo de que dependemos e que foi com frequência definido como 'dado', o enquadramento globalmente estável de nossas histórias e de nossos cálculos, é produto de uma história de coevolução ... E Gaia, 'planeta vivo', deve ser reconhecida como um 'ser', e não assimilada a uma soma de processos ... ela é dotada não apenas de uma história, mas também de um regime de atividades próprio, oriundo das múltiplas e emaranhadas maneiras pelas quais os processos que a constituem são articulados uns aos outros, a variação de um tendo múltiplas repercussões que afetam os outros (STENGERS, 2015, p. 38).

Stengers tampouco se satisfaz com Antropoceno. Centrais, tanto para ela quanto para Haraway, são a associação, a simbiose, processos articulados e uma certa imprevisibilidade das alianças. 
Há muitos casos de simbiose interessantes. Certamente, um dos mais importantes é a simbiose dos pólipos cnidários e das zooxantelas, dando vida às, muitas vezes extensíssimas, colônias de corais. São as zooxantelas, dinoflagelados fotossintéticos simbióticos, que, rudimente falando, alimentam o coral e é o processo de simbiose entre os dois animais que dá as cores das colônias.

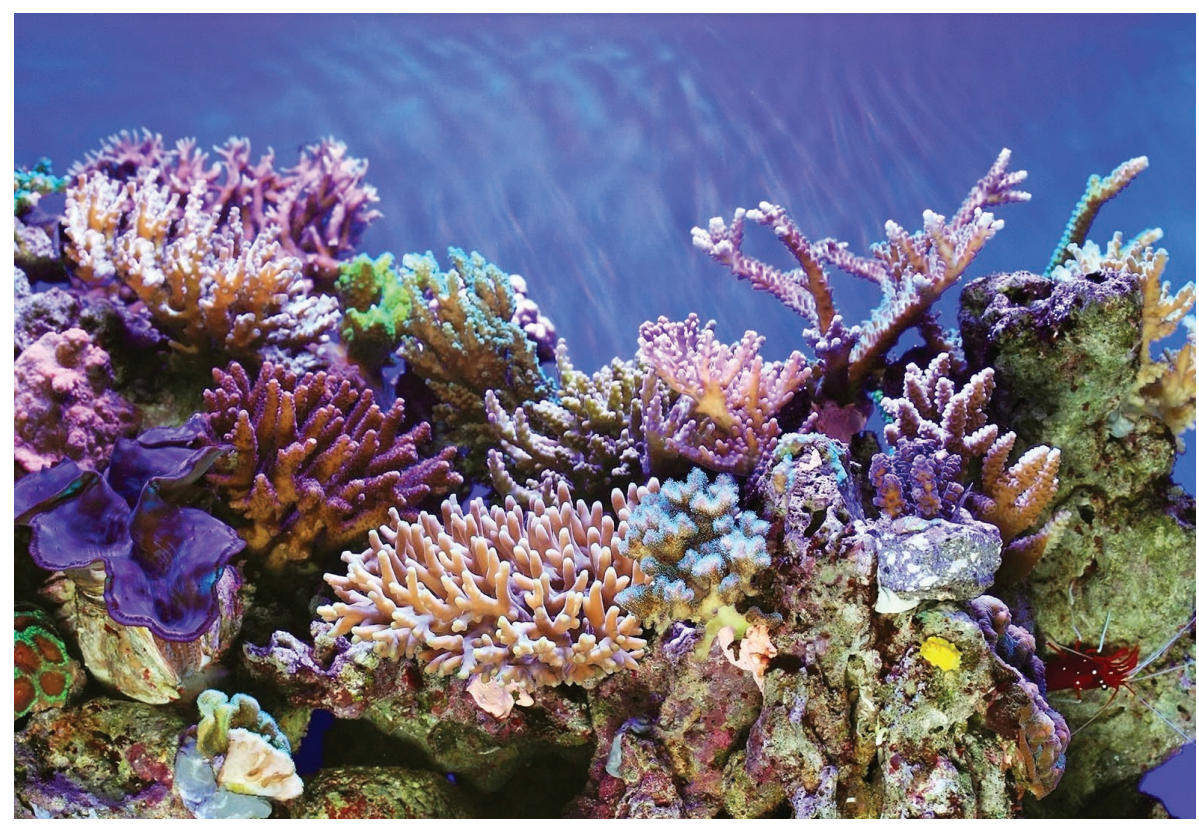

Figura 2. Recife de corais nas Ilhas Cayman (fonte: disponível em https://www. pinterest.pt/pin/716424253192842749/).

Esse caso específico de simbiose é importante para as narrativas da Chthulucene e de Gaia também porque os recifes de corais têm sido os seres que mais visivelmente sofrem com a acidificação dos oceanos e o aumento da temperatura das águas. São esses dois fatores que causam o branqueamento dos corais e sua eventual morte. Por sua vez, o reconhecimento da morte dos recifes de corais por essas razões foi uma das pedras basilares da proposta do termo Antropoceno no ano 2000. Mas para Haraway - para Chthulucene e para Gaia -, o que esses corais melhor ensinam é a interdependência entre criaturas, humanas e não humanas. "Corais, juntamente com os linquens, foram as primeiras instâncias de simbiose reconhecidas por biólogos; são estas as criaturas que ensinaram os biólogos a compreender o provincianismo das suas próprias ideias de indivíduos e coletividades" (HARAWAY, 2016, p. 72). 
O recife de coral nas figuras 3 e 4 faz parte do que é, provavelmente, o maior projeto colaborativo de arte do mundo, o Crochet Coral Reef. Haraway explica que 8 mil pessoas, a maioria mulheres, em 27 países, crochetam o que acaba por se transformar em modelos hiperbólicos que evocam potentemente os recifes de corais. "Estes corais operam não por mímica mas por um processo exploratório de fim indefinido" (HARAWAY, 2016, p. 78).
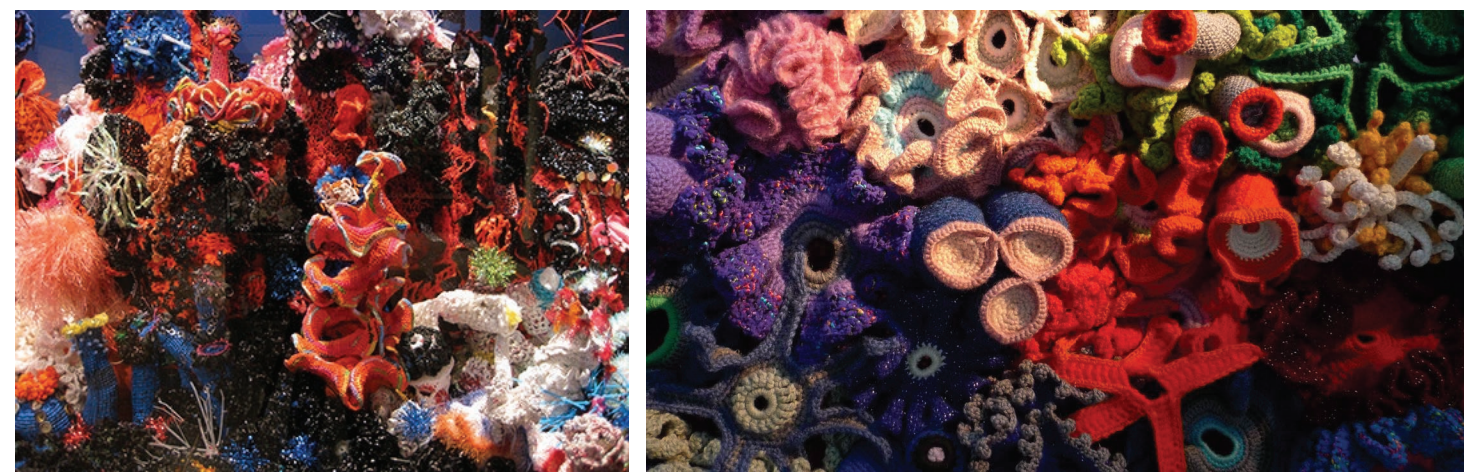

Figura 3 e 4. Crochet Coral Reef (fonte: disponível em http://crochetcoralreef.org/coral-reef-gallery.php).

Há uma série de narrativas possíveis sobre as relações entre os artesãos, e entre eles, os corais crochetados, os locais de exposição e os materiais usados - lã, algodão, plástico, fitas de bobinas. Além disso, há com os corais de verdade uma relação direta com 850 milhões de pessoas que dependem das ecologias dos recifes, segundo uma estimativa de setembro de 2015. O branqueamento dos corais e sua destruição faz parte, então, de um cenário de danos a múltiplas espécies.

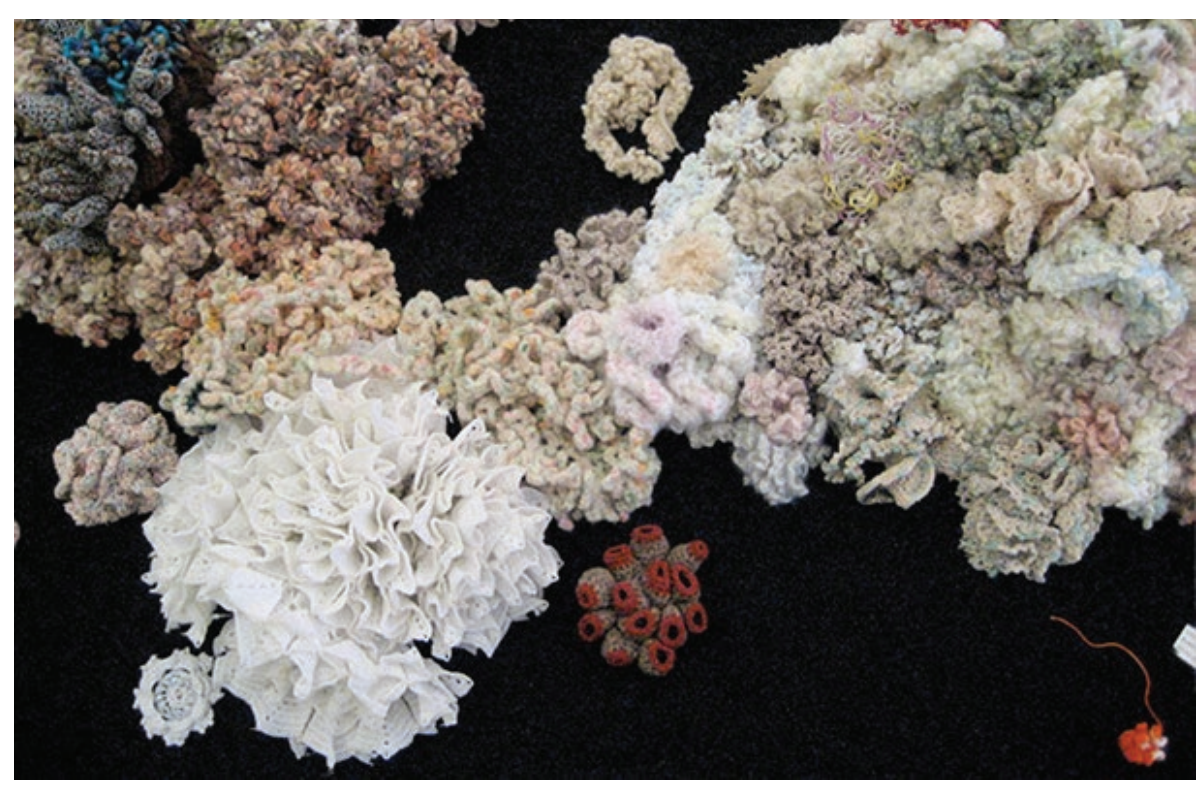

Figura 5. Crochet Coral Reef

(fonte: disponível em http://crochetcoralreef.org/coral-reef-gallery.php). 
Mas eu gostaria de pensar numa outra relação, bastante inusitada, mas que, se tudo der certo, fará sentido tanto para mim quanto para vocês. Na verdade, as razões dessa relação, ou melhor, as sensibilidades dessa relação são bastante evidentes.

Em abril deste ano, Beatriz Chachamovits, uma artista plástica paulistana, a autora da "Instrução para Simbiose", teve sua primeira exibição individual. Eu a havia conhecido há poucos anos, quando começava a pensar sobre as narrativas do planeta danificado de Donna Haraway, a sua Chthulucene. Chachamovits investe em criaturas que imagina em situações que mais ou menos conhecemos: o mar e o fundo do mar, principalmente. Seus peixes e suas paisagens nunca se mostram indivíduos ou sistemas fechados, mas organismos complexos formados pela simbiose entre muitas espécies, inclusive a humana, já que, também, é a artista que cria. Chachamovits aprende com a biologia, com os estudos moleculares. Atravessa disciplinas e chama atenção para aquele que se tornou o mais notável sítio das mudanças climáticas, o mar.

A exposição sobre a qual vou falar, "Mar Branco", começava de fora, antes de entrar na pequena Galeria, através da visão dos aquários-olhos-de-peixe, meias luas de acrílico que brotavam das paredes.

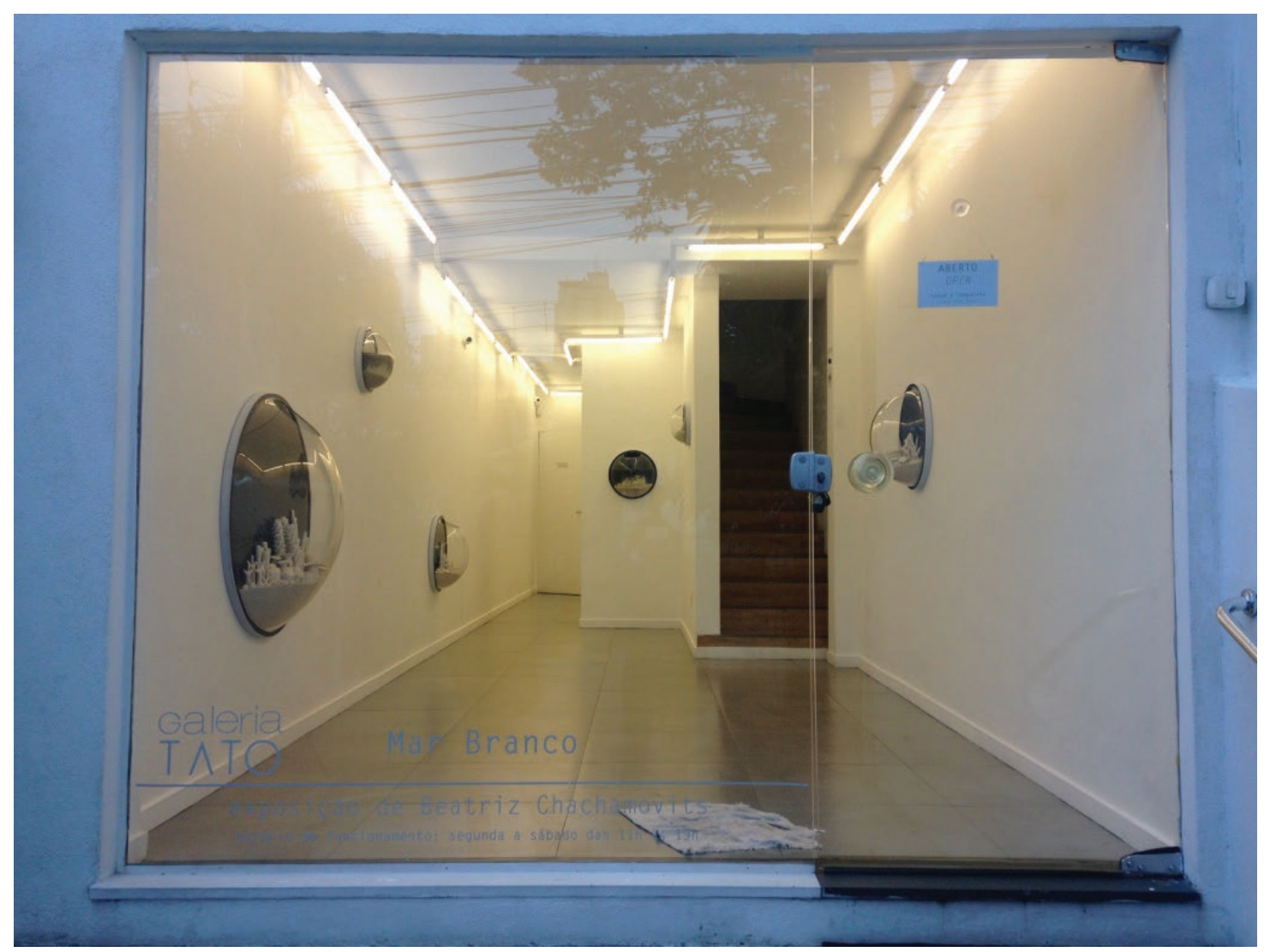

Figura 6. "Mar Branco" (fonte: arquivo pessoal - fotografia de Carolina Correia dos Santos/divulgação autorizada pela artista). 
Nestes áquarios redondos - alguns com água - estavam expostas as esculturas às quais Chachamovits se dedicou nos últimos anos. Cheguei a ver um pouco desse processo no começo. Era encantador como Beatriz apresentava suas esculturas: como pequenas joias, ela desembalava-as e me dizia que aquelas eram suas paixões, o que mais a afetava, aquilo que lhe solicitava.

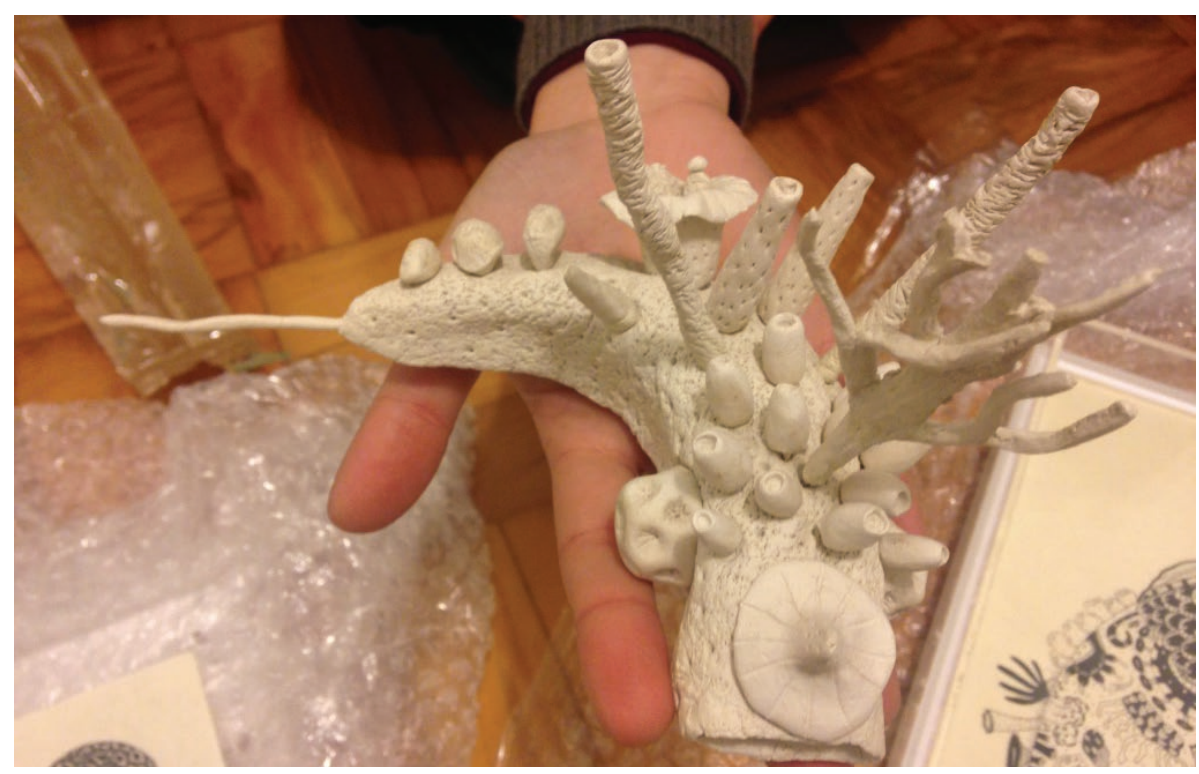

Figura 7. Beatriz Chachamovits mostra sua escultura (fonte: arquivo pessoal - fotografia de Carolina Correia dos Santos/divulgação autorizada pela artista).

Eu havia me interessado por seus desenhos e por isso a visitava em seu ateliê. Mas as esculturas apontavam um caminho relativamente novo, que se desenvolvia a partir dos mesmos interesses, mas que respondia a um anseio que ela explicitou dois anos depois, quando perguntei por qual razão havia preparado "Mar Branco": "Falo sobre o fundo do mar não somente porque sou apaixonada pelo seu mistério e fascinada por suas formas, mas por perceber que é um ambiente velado e que poucos falam sobre ele, mesmo sendo o ecossistema mais antigo e mais importante do planeta. Me preocupa saber que a maioria esmagadora das pessoas não tem noção do que se passa lá, e é tão incrível que decidi contar."

Mas a história que ela quis contar foi a história do branqueamento dos corais. Não é qualquer história; não começa nem termina na exposição ou ao vê-la. Na verdade, qualquer visita era única no sentido de que as esculturas na água respondiam à ação desta na massa que Beatriz resolveu usar para esculpir: se desmanchavam com o tempo. Não era uma simples alusão à destruição do holobioma coral, mas uma forte e dolorosa invocação da vida e da morte nos oceanos.

As esculturas respondiam à ação da água. Beatriz responde a um chamado afetivo, "me preocupa saber que a maioria esmagadora das pessoas não tem noção do que se passa lá, e é tão incrível”. Sua obra demonstra uma habilidade 
de responder, uma response-ability, como coloca Donna Haraway, ao planeta danificado. Chachamovits aproxima mundos aparentemente tão distintos quanto são uma galeria de arte em São Paulo e o mar dos recifes de corais. Na verdade, ela nos lembra que este ou aquele não é outro mundo, mas o nosso, o único que há e que ainda existe. Está agindo na e sobre a Chthulucene, que engendra narrativas do ainda-possível.
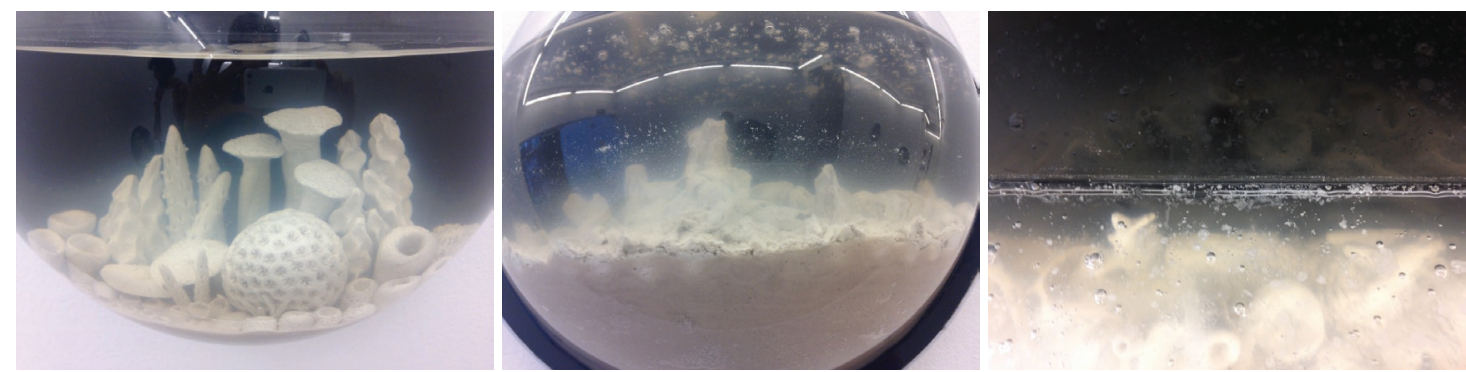

Figura 8, 9 e 10. "Mar Branco" (fonte: arquivo pessoal - fotografia de Carolina Correia dos Santos/divulgação autorizada pela artista).

"Mar Branco", eu dizia, não começa nem termina na visita à exposição, nem naquele espaço. Como na imagem da cama-de-gato, que Haraway evoca, acredito que podemos criar uma narrativa na qual Chachamovits é um dos personagens, ou jogadores, que, na sua vez, enfia os dedos por entre o barbante esticado pelo Crochet Coral Reef. Quero imaginar que Beatriz continua uma história, que "Mar Branco" é um resposta, também, ao Crochet Coral Reef, que a artista não conhece. E que, assim, ela faz parte de um processo aberto e com fim desconhecido. Ainda não sabemos como o mundo acaba, qual mundo acaba e se acaba.
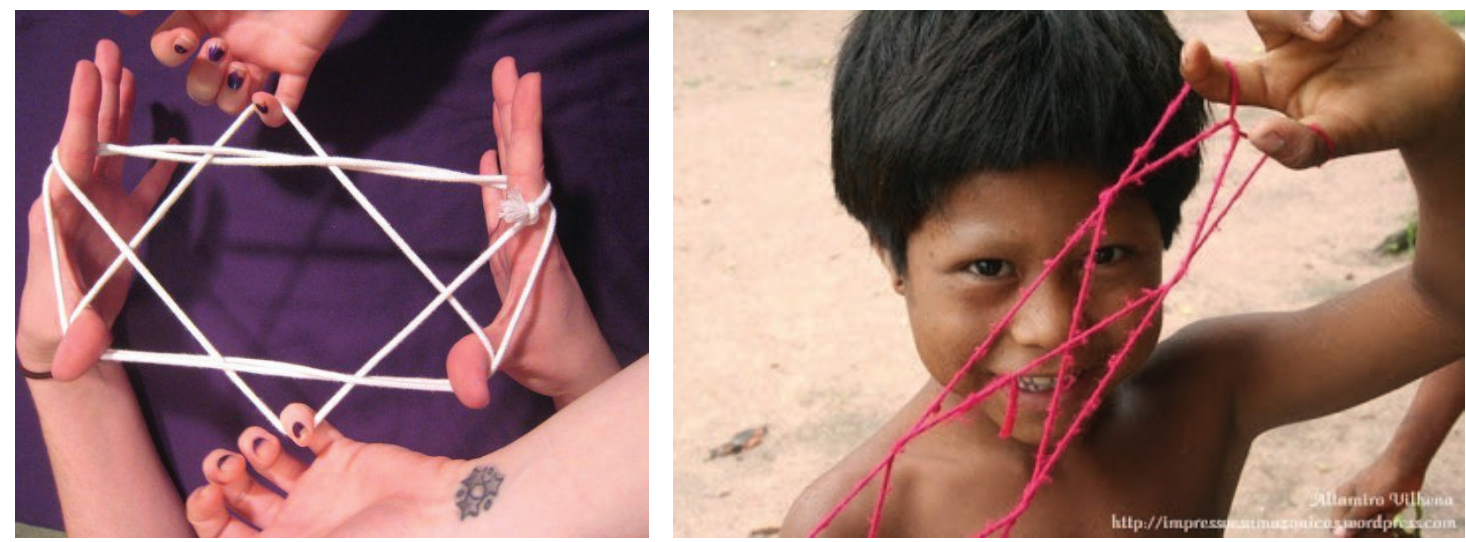

Figura 11. Jogo de cama-de-gato (fonte: imagem disponível em http://www.instructables.com/id/ Get-Wound-Up-In-Cats-Cradle/)

Figura 12. Criança indígena (fonte: fotografia de Altamiro Vilhena disponível em https://impressoesamazonicas.files.wordpress.com/2009/08/08-02-kendjan-39.jpg). 
Pensar a cama-de-gato é interessante por muitas razões. Por um lado, está a participação coletiva, um jogo de contínua-ação, onde os movimentos de um serão o material sobre o qual um outro agirá e onde todos são responsáveis. Por outro lado, este é um jogo presente em muitas culturas, provavelmente sem origem determinada, mas com ocorrências locais. Por isso fiz questão da foto da criança indígena. Por isso e porque os índios, e em especial os yanomami, têm uma narrativa de fim do mundo, que, não por coincidência é a mesma narrativa do começo do mundo. A imagem que criam - de um céu sustentado por muitos - é, ainda, muito próxima da cama de gato. Na verdade, todo o conhecimento yanomami é fundado sobre um conhecimento coletivo, construído por diversos atores. Davi Kopenawa, xamã yanomami, explica:

As palavras dos xapiri estão gravadas no meu pensamento, no mais fundo de mim. São as palavras de Omama. São muito antigas, mas os xamãs as renovam o tempo todo. ... Agora é minha vez de possuí-las. Mais tarde, elas entrarão na mente de meus filhos e genros, e depois, na dos filhos e genros deles. Então será a vez deles de fazê-las novas. Isso vai continuar pelos tempos afora, para sempre. Ficarão sempre no nosso pensamento ... Não envelhecerão como as que ficam coladas em peles de imagens tiradas de árvores mortas. Muito tempo depois de eu já ter deixado de existir, elas continuarão tão novas e fortes como agora (KOPENAWA, 2015, p. 66).

Trago mais este ator à narrativa que teço, mas Kopenawa e principalmente A queda do céu, complexificam a ideia de que este seja, apenas, mais um ator. Diferente, mas um pouco ao modo como o Crochet Coral Reef é resultado do trabalho de milhares de pessoas, este ator tampouco é indivíduo. Para começar, A queda do céu: palavras de um xamã yanomami é um livro escrito por Bruce Albert, um etnólogo francês, com Kopenawa. Albert já tinha uma longa história com os yanomami quando passa a ouvir os relatos de Kopenawa, gravados em fitas k7. Kopenawa teria visto uma reportagem na TV sobre os garimpos abertos ilegalmente em território yanomami. Chocado, haveria dito à antropóloga que o recebia em Brasília naquela instância: "Os brancos não sabem sonhar, é por isso que destroem a floresta desse jeito" (ALBERT, KOPENAWA, 2015, p. 531). Por sugestão dessa antropóloga, Alcida Ramos, Kopenawa passara a gravar o que teria a dizer, em yanomami, a Albert. A relação entre os dois - tão compatível com a ideia de simbiose e mesmo um dos agenciamentos que constitue Gaia, para retomar a definiçao de Stengers - assim como a própria ideia de autoria, que é tão cara ao homem moderno, de A queda do céu 
se complexifica mais porque, como explica Kopenawa, muitos são os usuários, os receptores e inovadores das palavras de Omama. E as palavras de Omama são "as palavras de um xamã yanomami” que lemos. Como na cama-de-gato, numa relação simbiótica, ou sim-poiética, um fazer-com, muitos agentes são os responsáveis pelo jogo, pela narrativa do mundo.

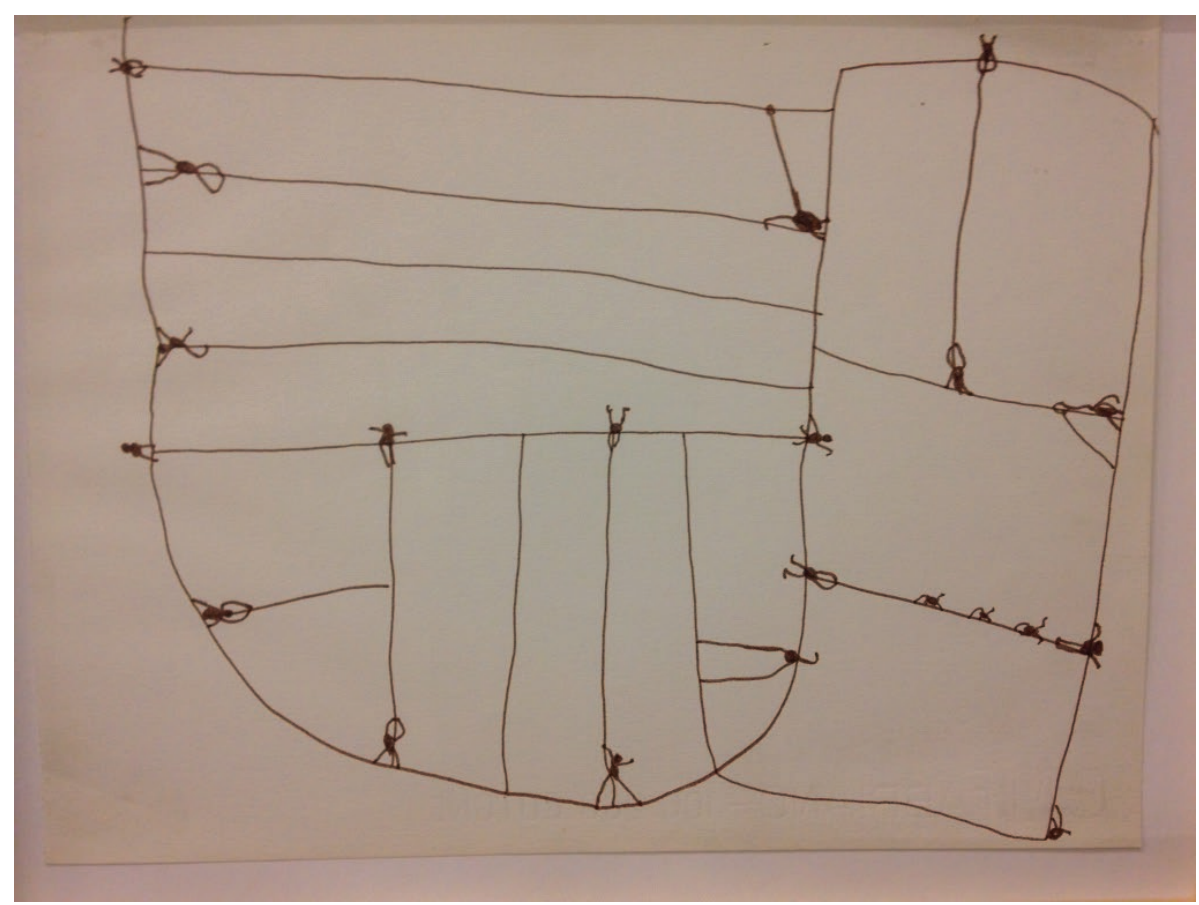

Figura 13. Desenho yanomami, pavilhão Claudia Andujar, Inhotim (fonte: arquivo pessoal - fotografia de Carolina Correia dos Santos).

Importa quais pensamentos pensam pensamentos. Importa quais conhecimentos conhecem conhecimentos. Essas são duas das premissas de Donna Haraway (2016) nestes tempos de Antropoceno, quando não é mais a figura do pós-humano que interessa, mas a do "humus", da "com-postagem". Kopenawa me ajuda a pensar pensamentos, com suas palavras escrevo:

Não falo da floresta sem saber. Contemplei a imagem da fertilidade de suas árvores e a da gordura de seus animais de caça. Escuto a voz dos espíritos abelha que vivem em suas flores e a dos seres do vento que mandam para longe as fumaças de epidemia. Faço dançar os espíritos dos animais e dos peixes. Faço descer a imagem dos rios e da terra. Defendo a floresta porque a conheço, graças ao poder da yãkoana" (KOPENAWA, 2015, p. 391). 
O conhecimento evocado por Kopenawa se volta a outros seres e outras práticas de conhecimento. Importa que conhecimentos conhecem e um yanomami conhece no sonho, nos transes induzidos pela yãkoana. Suas histórias são necessárias. "Think we must”, diz Haraway. "Precisamos sonhar", diria Kopenawa. "Os brancos não sabem sonhar, é por isso que destroem a floresta desse jeito", haveria dito à Alcida Ramos.

A história que conta Kopenawa não lhe pertence com exclusividade. Ele não é seu único autor, nem seu único enunciador. E a história do fim do mundo que contam os yanomami tem essa linda particularidade de ser, também, a história do começo do mundo. Em tempos de Antropoceno, Haraway apaixonadamente clama por histórias de urgências e não de emergências. Histórias que habitem as temporalidades das urgências, outras temporalidades; pensamentos que consigam ser pensados, engajando conhecimentos não refutáveis e o desejo pela presença; histórias, enfim, que não se tornem mitos auto-indulgentes e auto-realizadores do apocalipse. Me parece que os mitopoemas yanomami: "O Fim do Mundo" e os dois "Começo do Mundo", operando sobre a mesma queda do céu, nos oferece um cenário mais caótico, mais complexo e mais ambíguo que um armagedom.

O Fim do Mundo.

Tubo acaba.

Desaparecerá o céu.

Cairá com todos os napèpe.

Tudo acaba.

Tudo cai, desce de cima.

Tudo acaba, indo para o fundo.

Tudo cai e acaba

Esta camada fina do céu,

que está em cima, descerá

o céu irá para o fundo.

Todos choram muito.

Todos os napèpe caem.

Tudo acaba.

Depois não terá mais Yanomami.

$O$ céu enorme cai.

$O$ céu todo desce e desaparece.

Năo há mais Yãnomam.

Os pés do céu:

lá um pé do céu é fincado,

lá outro pé do céu é fincado.

lá outro pé do céu é fincado, longe.

lá outro pé do céu é fincado.

O céu todo cai.

Todos choram

O céu acabará

As estruturas sustinham o céu.

O céu cai.

O céu acabará todo.

\section{Começo do Mundo}

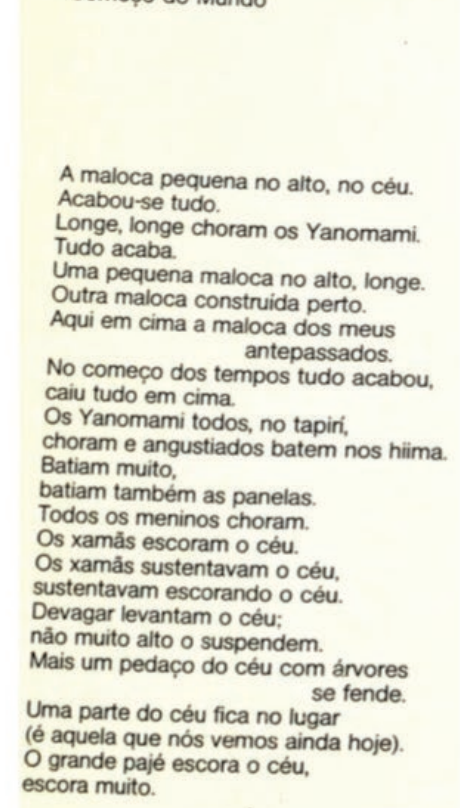

Começo do Mundo

Toda uma grande parte do

Tudo acabou se fendeu.

Tudo acabou.

Os pés do céu estão distantes.

0 céu que está em cima está escorado neles.

O céu está suspenso no alto.

Suas pernas de pau se fincam no chão. tra fenda no céu que está

0 céu racha ainda mais umailhas.

0 tempo está numo novo.
de numa

Tempo está nublado.

Tudo acabou.

Não existe mais mato.

A floresta, tombando,

fez um buraco na terra e foi parar muito fundo.

As árvores de folhas pequenas,

raízes de fora e tronco curto,

ao cairem, racharam-se ao meio.

No alto do céu ainda restou água;

a água da chuva.

Figura 14. Mitopoemas Yanomami (fonte: arquivo pessoal - fotografia de Carolina Correia dos Santos do livro organizado pela Comissão Pro Yanomami / Claudia Andujar). 
Esses poemas narrativos têm um quê de revolucionário, são mitopoemas. E nisso a literatura - pois falamos de narrativas e histórias aqui e estudá-las é também estudar literatura - os imita. Também ela quer invocar um neutro, a interdição do "eu”. Também ela quer tornar-se alguma outra coisa. "Escrever é também tornar-se outra coisa que não escritor”, diz Deleuze. Por isso, lembra: "Aos que lhe perguntam em que consiste a escrita, Virginia Woolf responde: Quem fala de escrever? O escritor não fala disso, está preocupado com outra coisa (DELEUZE, 2011, p.17).

A narrativa que engendrei aqui conjugou atores improváveis mas próximos. Em minha defesa, Isabelle Stengers diria que é importante "aprender e cultivar o cuidado, cultivar no sentido em ... que ele obriga a imaginar, sondar, atentar para consequências que estabeleçam conexões entre o que estamos acostumados a considerar separadamente" (STENGERS, 2015, p.55). Stengers fala disso quando pensa na falta de cuidado necessária para levar a cabo o "desenvolvimento" (econômico). Mas acredito que podemos pensar em cultivar o cuidado para imaginar narrativas entre seres que parecem separados entre si. É, afinal, este momento de urgência multiespécie que motiva todos os atores e toda a arte que mencionei ou aludi aqui. Inclusive eu mesma.

Citei os desenhos de Chachamovits, que primeiro me chamaram a atenção. Em "Mar Branco", ela também apresentou alguns, além das esculturas. Eles faziam parte dos seus infográficos.

Deixei-os para o final porque, me parece, que eles, mais do que qualquer outra obra, sejam multiespécies.

É possível que Chachamovitsw nos desse uma resposta parecida à de Virginia Woolf, resposta que Deleuze menciona como um tipo de súmula do desejo do escritor. A quem lhe perguntasse em que consiste o desenho, Beatriz talvez respondesse: "Mas quem fala de desenhar? Estou preocupada com outra coisa."
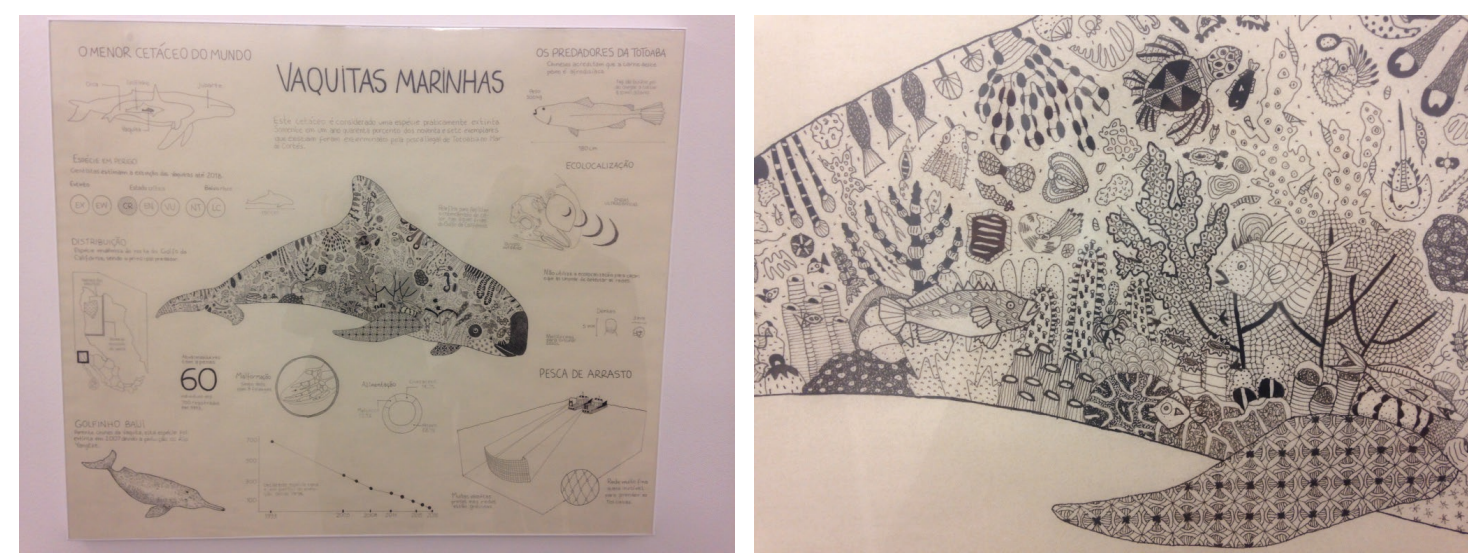

Figura 15 e 16. "Mar Branco" (fonte: arquivo pessoal - fotografia de Carolina Correia dos Santos/divulgação autorizada pela artista). 


\section{Referências}

ALBERT, B.; KOPENAWA, D. A queda do céu: palavras de um xamã yanomami. São Paulo: Companhia das Letras, 2015.

DELEUZE, G. A literatura e a vida. In: Crítica e clínica. Trad. Peter Pál Pelbart. São Paulo: Editora 34, 2011.

HARAWAY, D. J. Staying with the Trouble: Making Kin in the Chthulucene. Durham and London: Duke University Press, 2016.

STENGERS, I. No tempo das catástrofes. Trad. Eloisa Araujo. São Paulo: Cosac Naify, 2015.

STRATHERN, M. O gênero da dádiva: problemas com as mulheres e problemas com a sociedade na Melanésia. Trad. André Villalobos. Campinas: Editora Unicamp, 2006.

YANOMAMI, K. W.; YANOMAMI, M. R.; YANOMAMI, K. W. Mitos Yanomam. Pesquisa e coordenação Claudia Andujar. Transcrição e Trad. Carlo Zacquini. São Paulo: Comissão pela criação do Parque Yanomami, 1987. 


\section{Como citar}

SANTOS, Carolina Correia dos. Instrução para Simbiose. Arcos Design. Rio de Janeiro: PPD ESDI - UERJ. Edição Especial Outubro 2017. pp. 39-54. Disponível em: [http://www.e-publicacoes.uerj. br/index.php/arcosdesign]

DOI: $10.12957 /$ arcosdesign.2017.30940

\section{(c) (1) (2) (2)}

A Revista Arcos Design está licenciada sob uma licença Creative Commons Atribuição - Não Comercial - Compartilha Igual 3.0 Não Adaptada. 